\title{
MiR-378 is an independent prognostic factor and inhibits cell growth and invasion in colorectal cancer
}

\author{
Guang-jun Zhang ${ }^{1,2+}$, He Zhou ${ }^{1,2+}$, Hua-Xu Xiao ${ }^{3}$, Yu Li ${ }^{4}$ and Tong Zhou ${ }^{1,2^{*}}$
}

\begin{abstract}
Background: MicroRNAs(miRNAs) are small non-coding RNAs that participate in a variety of biologic processes, and dysregulation of miRNA is always associated with cancer development and progression. Aberrant expression of miR-378 has been found in some types of cancer. However, effects and potential mechanisms of miR-378 in colorectal cancer (CRC) have not been explored.

Methods: Quantitative RT-PCR was performed to evaluate miR-378 levels in CRC cell lines and 84 pairs of CRC cancer and normal adjacent mucosa. Kaplan-Meier and Cox proportional regression analyses were utilized to determine the association of miR-378 expression with survival of patients. MTT and invasion assays were used to determine the role of miR-378 in regulation of CRC cancer cell growth and invasion, respectively. Tumor growth was assessed by subcutaneous inoculation of cells into BALB/c nude mice. Luciferase assay was performed to assess miR-378 binding to vimentin gene.
\end{abstract}

Results: In this study, we confirmed that miR-378 significantly down-regulated in CRC cancer tissues and cell lines. Moreover, patients with low miR-378 expression had significantly poorer overall survival, and miR-378 expression was an independent prognostic factor in CRC. Over-expression of miR-378 inhibited SW620 cell growth and invasion, and resulted in down-regulation of vimentin expression. However, miR-378 knock-down promoted these processes and enhanced the expression of vimentin. In addition, we further identified vimentin as the functional downstream target of miR-378 by directly targeting the 3'-UTR of vimentin.

Conclusions: In conclusion, miR-378 may function as a tumor suppressor and plays an important role in inhibiting tumor growth and invasion. Our present results implicate the potential effects of miR-378 on prognosis and treatment of CRC cancer.

Keywords: Colorectal cancer, miR-378, Vimentin, Invasion, Prognosis

\section{Background}

Colorectal cancer (CRC) is one of the most common malignancies worldwide, and it has high mortality and prevalence rates in East Asian countries including China [1]. Metastasis is the major cause of CRC morbidity and mortality, and more than one-third of patients with CRC will ultimately develop metastatic disease [2]. An urgent

\footnotetext{
* Correspondence: zhoutong0088@163.com

${ }^{\dagger}$ Equal contributors

${ }^{1}$ The First Department of General Surgery, The Affiliated Hospital of North Sichuan Medical College, Nanchong, Sichuan, People's Republic of China ${ }^{2}$ Institute of Hepatobiliary, Pancreatic and Intestinal Disease, North Sichuan Medical College, Nanchong, Sichuan, People's Republic of China

Full list of author information is available at the end of the article
}

need to search for specific, sensitive biomarkers for the early diagnosis and prognosis prediction of CRC exists.

miRNAs are a class of small non-coding RNAs, which contain of about 22 nucleotides. miRNAs bind to partially complementary sequences in the 3 -untranslated region (UTR) of specific target mRNA, resulting in either mRNA degradation or translation inhibition [3]. Growing evidence suggests that miRNAs play an important role in various biologic processes, including cell proliferation, development, and differentiation [4,5]. Furthermore, increasing numbers of miRNAs have been observed in various types of cancer and may be involved in modulating cancer cell behaviors [6-9]. These data emphasize the importance of

\section{Biomed Central}

(c) 2014 Zhang et al.; licensee BioMed Central Ltd. This is an Open Access article distributed under the terms of the Creative Commons Attribution License (http://creativecommons.org/licenses/by/2.0), which permits unrestricted use, distribution, and reproduction in any medium, provided the original work is properly credited. 
miRNAs in cancer development and provide new insights into understanding the molecular mechanism of tumorigenesis.

Alterations in miRNA expression have been suggested to play important roles in tumorigenesis and cancer progression [10]. Recently, miR-378 expression was shown to be deregulated in oral carcinoma and renal cell carcinoma [11,12]. The involvement of miR-378 in the tumorigenesis and metastasis of glioblastoma, non-small cell lung cancer, breast cancer and gastric cancer has also been reported [13-16]. Previous reports revealed that the miR-378 was down-regulated in CRC [17-20]. However, to our knowledge, its biological role and clinical significance in colorectal cancer remain undefined.

Therefore, in this study, we confirmed the expression of miR-378 in fresh CRC tissue specimens and CRC cell lines by using qRT-PCR. After that, we assessed the clinical significance of miR-378 in colorectal cancer, and to investigate the effects of miR-378 on CRC cells growth and invasion and further discuss the mechanisms of action of miR-378 by identifying its potential target gene.

\section{Methods}

Patients and tissue samples

Surgical specimens of cancer tissue and adjacent normal mucosa were obtained from 86 patients with colorectal cancer who underwent surgery at The Affiliated Hospital of North Sichuan Medical College between 2005 and 2008. Among the 86 patients, 2 patients diagnosed with distant metastases were excluded from our study because these cases were too few for meaningful statistical analysis. None of the patients had received chemotherapy or radiotherapy before surgery excision. After collection, all tissue samples were immediately frozen in liquid nitrogen and stored at $-80^{\circ} \mathrm{C}$ until use. Tumor stage was classified according to the International Union against Cancer (UICC, 6th ed., 2002). Informed written consent was obtained from each patient, and research protocols were approved by the Medical Ethics Committee of North Sichuan Medical College.

\section{Cell culture}

The human CRC cell lines HT29, HCT116, SW480, SW620 and the normal colon epithelium cell line CCD18Co were obtained from the American Type Culture Collection and cultured in DMEM medium supplemented with $10 \%$ fetal bovine serum, $100 \mathrm{u} / \mathrm{ml}$ penicillin and $100 \mathrm{mg} / \mathrm{ml}$ streptomycin, at $37^{\circ} \mathrm{C}$ in a humidified atmosphere of $5 \% \mathrm{CO}_{2}$.

\section{RNA extraction and real-time RT-PCR}

Total RNA was extracted using TRIzol reagent (Invitrogen, Carlsbad, CA, USA). The PCR primers for miR-378 and U6 were purchased from Applied Biosystems (ABI,
Foster City, CA, USA). The PCR primers for vimentin were 5'-GAGAACTTTGCCGTTGAAGC-3' and 5'-GCTTCC TGTAGGTGGCAATC-3'. The primers for $\beta$-actin: $5^{\prime}$-CC AAGGCCAAC CGCGAGAAGATGAC-3' and 5'-AGGG TACATGGTGGTGCCGCCA GAC-3'. The first-strand cDNA was synthesized using the PrimeScript RT reagent Kit (TaKaRa, Dalian, China). Real-time PCR was performed using SYBR Premix Ex Taq (TaKaRa) and measured in a LightCycler 480 system (Roche, Basel, Switzerland). U6 or $\beta$-actin was used as internal control. Relative quantification of microRNA expression was calculated using the $2^{-\Delta \Delta C T}$ method.

\section{Transfection of miRNA}

The pre-miR miRNA-378(Pre-miR-378), pre-miR negative control (Pre- miR-nc), anti-miR negative control (anti-miR-nc) and anti-miR-378 inhibitor (anti-miR-378) were purchased from Ambion (Austin, TX,USA). $2 \times 10^{5}$ cells were seeded into each well of a 6-well plate and transfected for $24 \mathrm{~h}$ or $48 \mathrm{~h}$ using Lipofectamine 2000 reagent (Invitrogen) following manufacturer's protocol. Transfected cells were used in further assays or RNA/ protein extraction.

\section{MTT assay}

A total of $2 \times 10^{4} \mathrm{SW} 620$ cells were plated onto 96-well plates for $24 \mathrm{~h}$. The cells were then transfected with 50 $\mathrm{nM}$ the indicated miRNA. At different time points ( $24 \mathrm{~h}, 48 \mathrm{~h}$ and $72 \mathrm{~h}$ ), the culture medium was removed and replaced with culture medium containing $10 \mu \mathrm{l}$ of sterile MTT dye $(5 \mathrm{mg} / \mathrm{ml})$. After incubation at $37^{\circ} \mathrm{C}$ for $4 \mathrm{~h}$, the MTT solution was removed, and $150 \mu \mathrm{l}$ dimethyl sulfoxide (DMSO) was added to each well followed by measuring the absorbance at $570 \mathrm{~nm}$ on an enzyme immunoassay analyzer (Bio-Rad, Hercules, CA, USA).

\section{Matrigel invasion assay}

Cell invasion experiment was assessed using the Matrigel Invasion Chamber of pore size $8 \mathrm{~mm}$ (Corning Costar Corporation, Cambridge, MA, USA). A total of $5 \times 10^{4}$ cells were seeded into the upper compartment of the chamber coated with $150 \mu \mathrm{g}$ of Matrigel (BD Biosciences, Bedford, MD,USA). Medium containing $10 \%$ fetal bovine serum in the lower chamber served as the chemoattractant. After the cells were incubated for 48 hours and fixed and stained with hematoxylin for 30 minutes, and the non-invaded cells were removed with cotton swabs. The number of invasive cells on the lower surface of the membrane was then counted under a microscope at a magnification of $\times 400$ in 5 random fields. 


\section{In vivo xenograft experiments}

Female BALB/C nude mice at the age of 4 weeks purchased from the Shanghai Laboratory Animal Center (Chinese Academy of Sciences) were randomly divided into 2 groups (five mice per group). All the procedures involving animals were approved by Experimental Animal Ethics Committee, North Sichuan Medical College. Pre-miR-378 or pre-miR-nc stable transfection SW620 cells suspensions $\left(1 \times 10^{6}\right.$ cells $\left./ \mathrm{ml}\right)$ in $200 \mu \mathrm{l}$ serum-free medium were subcutaneously injected into the flanks of nude mice, respectively. Tumor growth was examined twice per week for 5 weeks and tumor volumes were calculated using the formula Volume $\left(\mathrm{mm}^{3}\right)=\mathrm{L} \times \mathrm{W}^{2} / 2$ (length L, mm; width $\mathrm{W}, \mathrm{mm})$. After 5 weeks, tumor samples were carefully removed and weighed.

\section{Western blot analysis}

Immunoblotting was performed to detect the expression of vimentin in CRC cell lines. Transfected cells were lysed in RIPA lysis buffer (ProMab Biotechnology). Protein was loaded onto a SDS-PAGE minigel and transferred onto PVDF membrane. After probed with 1:500 diluted mouse anti-vimentin (Santa Cruz Biotechnology, Santa Cruz, CA, USA) at $4^{\circ} \mathrm{C}$ overnight, the blots were subsequently incubated with HRP-conjugated secondary antibody (1:5000). Signals were visualized using ECL Substrates (Millipore, MA, USA). GAPDH was used as an endogenous protein for normalization.

\section{Dual-luciferase reporter assay}

For luciferase reporter experiments, the wild-type and mutated 3'UTR of vimentin mRNA were subcloned into the XhoI and NotI site of the psicheck-2 vector (Promega) and the new vectors were named psicheck-2vimentin-WT and psicheck-2-vimentin-MUT, respectively. The following primers were used to amplify specific fragments: vimentin-WT, forward 5' - CACAACTCGAGTTG CACACACTCAGTG CAGC-3' and reverse 5' - AAGG AAAAAAGCGGCCGCCAAGTTGG TTGGATACTTGC TGG-3' and vimentin-MUT, forward 5'- GTTTTAG TC CTGCGCAAGATAGATTTGGAATAGGA-3' and Reverse 5' - TGC GCAGGACTAAAACTGCAGAAAGGCACTTG AAAGCTG-3'. For reporter assay, HEK 293 T cells were plated onto 24 -well plates at $2 \times 10^{4}$ cells/well and transfected with $200 \mathrm{ng}$ of psicheck-2-wimentin-WT or psicheck-2-vimentin-MUT and $40 \mathrm{nM}$ pre-miR-378 or pre-miR-nc using Lipofectamine 2000 (Invitrogen). Firefly luciferase was used to normalize the Renilla luciferase. After transfection for $48 \mathrm{~h}$, cells were harvested and assayed with Dual-Luciferase Reporter Assay System (Promega) according to the manufacturer's protocols.

\section{Statistical analysis}

All data presented in this study have been repeated at least three times from three independent experiments. Continuous variables were expressed as the mean \pm standard deviation. The differences between groups were analyzed using student's $t$-test, while categorical data were studied using chi-square test. The postoperative survival rate was analyzed with Kaplan-Meier method, and differences in survival rates were assessed with logrank test. A Cox proportional hazards model was used for multivariate analysis. All statistical analyses were performed using SPSS 16.0 software (SPSS, Chicago, IL, USA). Two-sided $P$-values were calculated, and differences were considered significant at $P$-values of $<0.05$.

\section{Results}

The miR-378 expression in CRC tissues and cell lines

We performed quantitative PCR analysis to detect the expression level of miR-378 in CRC tissues and cell lines. In 84 cases of primary CRC tissues and their adjacent normal colonic tissues, our results showed that miR-378 was significantly decreased in CRC tissues $(1.31 \pm 0.57)$ when compared with that in the paired adjacent normal tissues $(2.82 \pm 1.12)(P<0.01$, Figure $1 \mathrm{~A})$. The expression of miR-378 was then assessed in four CRC cell lines (SW620, SW480, HT29 and HCT116) and the normal colon epithelium cell line CCD-18Co. The results showed that the level of miR-378 was lower in all four CRC cell lines compared with normal colon cell line (Figure 1B).

\section{Correlation between miR-378 expression and clinical features and prognosis of CRC patients}

To evaluate the correlation between miR-378 expression and clinicopathological characteristics, the 84 patients with CRC cancer were classified into two groups according to the median expression (2.77) of miR-378. We compared the clinicopathological factors of the high and low miR-378 expression group (Table 1) and found that low expression of miR-378 was significantly correlated with large tumor size $(P=0.035)$, positive lymph node metastasis $(P=0.004)$, and advanced clinical stage $(P=0.017)$.

Kaplan-Meier survival analysis showed that low miR-378 expression correlated with shorter overall survival (Figure 2, $P=0.004$ ). Univariate proportional hazard model revealed a statistically significant correlation between overall survival and miR-378 level, tumour size, local invasion, lymph node metastasis, and TNM stage (Table 2). The parameters that significantly correlated with survival in the univariate analysis were further assessed by multivariate analysis. Since TNM stage is determined by the local invasion and lymph node metastasis, it was not further enrolled 


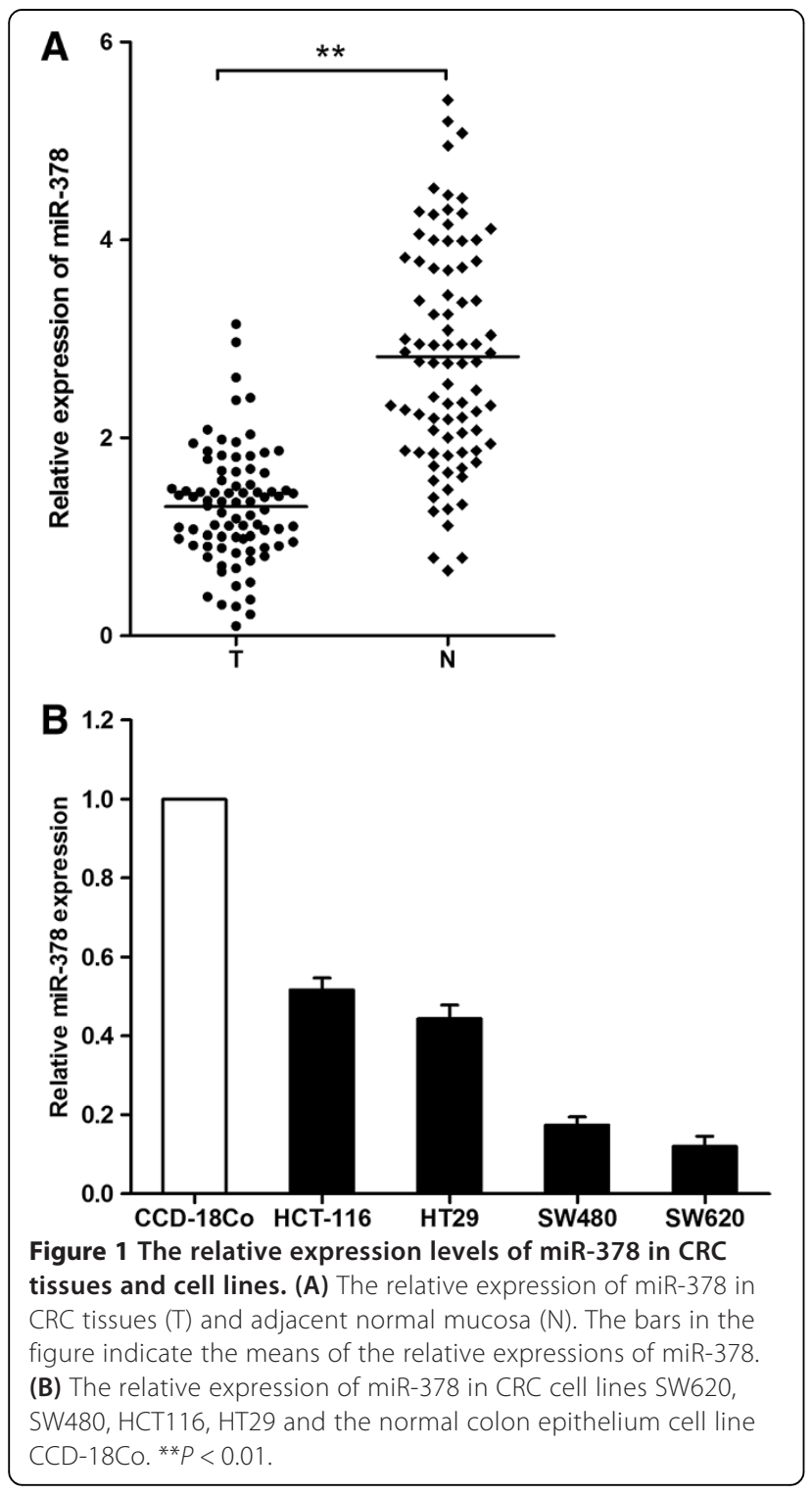

into the multivariate analysis in this study, and the results of the multivariate analysis demonstrated that miR-378 $(P=0.037)$ and lymph node metastasis $(P=$ $0.001)$ were independent prognostic factors for overall survival (Table 2). These results indicated that miR378 may be involved in the progression of CRC and predict overall survival in CRC.

Effect of miR-378 on CRC cell growth and invasion in vitro To validate if miR-378 regulates CRC cell growth, we performed a proliferation assay by transfecting pre-miR378 or pre-miR-nc into SW620 cells. It showed that the increased expression of miR-378 induced significant inhibition on cell proliferation (Figure 3A). Correspondingly, after transfected with anti-miR-378, SW620 cells presented stimulated cell growth compared to scramble
Table 1 Association of miR-378 expression with clinicopathologic factors of colorectal cancer patients

\begin{tabular}{|c|c|c|c|}
\hline \multicolumn{4}{|c|}{ miR-378 expression } \\
\hline Variable & Low $(n=42)$ & High $(n=42)$ & $P$-value \\
\hline Age (years) & & & 0.268 \\
\hline$\leq 60$ & 15 & 20 & \\
\hline$>60$ & 17 & 22 & \\
\hline Gender & & & 0.378 \\
\hline Male & 26 & 22 & \\
\hline Female & 16 & 20 & \\
\hline Tumor size & & & 0.035 \\
\hline$\leq 5 \mathrm{~cm}$ & 24 & 33 & \\
\hline$>5 \mathrm{~cm}$ & 18 & 9 & \\
\hline Histological grading & & & 0.172 \\
\hline Well, moderate & 24 & 30 & \\
\hline Poor, mucinous & 18 & 12 & \\
\hline Depth of invasion & & & 0.275 \\
\hline $\mathrm{T} 1-\mathrm{T} 2$ & 19 & 24 & \\
\hline T3-T4 & 23 & 18 & \\
\hline Clinicopathological staging & & & 0.017 \\
\hline 1 & 4 & 14 & \\
\hline$\|$ & 9 & 12 & \\
\hline III & 29 & 16 & \\
\hline Location & & & 0.355 \\
\hline Colon & 12 & 16 & \\
\hline Rectum & 30 & 26 & \\
\hline Lymph node metastasis & & & 0.004 \\
\hline Negative & 13 & 26 & \\
\hline Positive & 29 & 16 & \\
\hline
\end{tabular}

well: well-differentiated, moderate: moderately differentiated, poor: poorly differentiated, mucinous: mucinous carcinoma.

control (Figure 3C). Cell motility of transfected cells was evaluated by invasion assay. As shown in Figure 3B, compared to the scramble control, pre-miR-378 transfected SW620 cells exhibited significant impairment of invasive ability. Inversely, down-regulation of miR-378 in inhibitors transfected SW620 cells apparently promoted cell invasion (Figure 3D).

\section{MiR-378 inhibits tumor growth in vivo}

To examine the role of miR-378 in CRC tumor development, we used a BALB/C nude xenograft mouse model in which mice were transplanted with pre-miR-378 and pre-miR-nc transfected cells. After 5 weeks, miR-378 over-expressing tumors were significantly smaller than those of mice transfected with scramble control (Figure 4A). Furthermore, overexpression of miR-378 significantly reduced xenograft tumor volume (Figure $4 \mathrm{~B}$ ) and tumor weight (Figure 4C). 


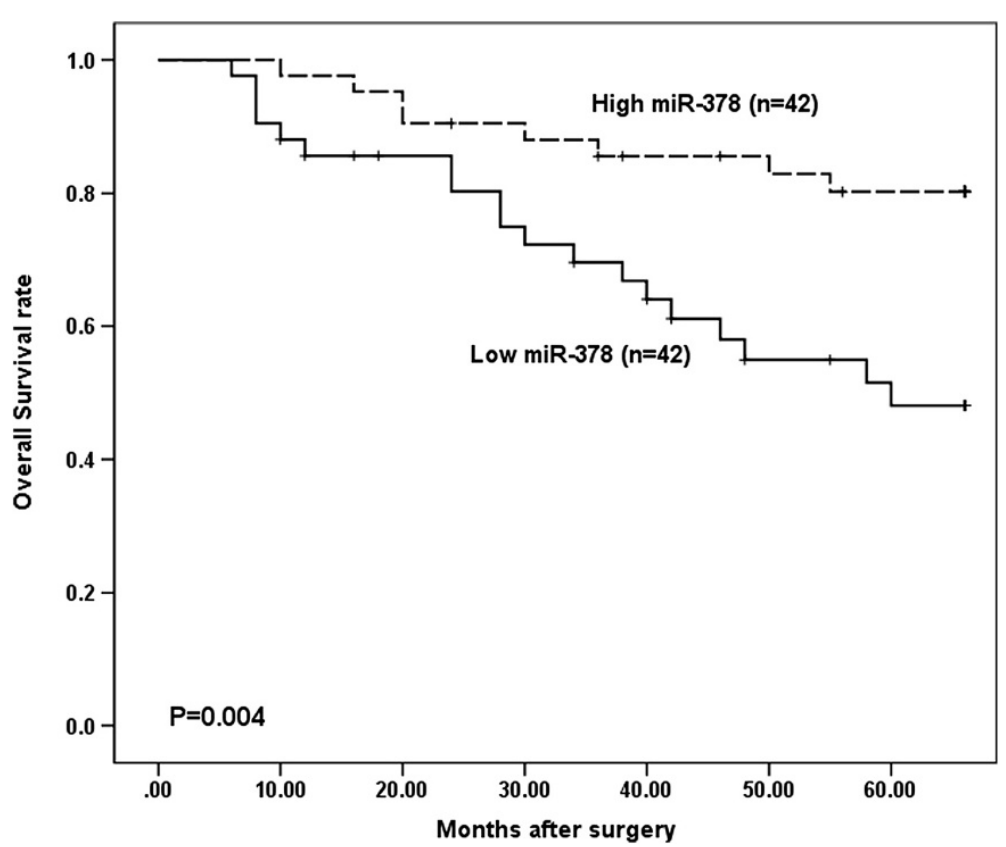

Figure 2 Kaplan-Meier survival curves of patients with colorectal cancer based on miR-378 expression status. Patients in the low expression group had significantly poorer prognosis than those in high expression group ( $P=0.004$, log-rank test).

\section{Vimentin is a direct target of miR-378}

To understand the possible mechanisms that might underlie miR-378-mediated growth and metastasis suppression, we performed in silico studies to search for potential gene targets of miR-378 using the bioinformatics algorithms Pictar and miRanda. All of the algorithms indicated that vimentin was a theoretical target of miR378 (Figure 5A).

To further confirm that vimentin is the direct target of miR-378, we first determined whether over-expression of miR-378 can lead to down-regulation of vimentin expression. We transfected SW620 cells with pre-miR-378 or anti-miR-378, Western blot showed that the enhanced miR-378 expression in SW620 cells significantly repressed vimentin protein expression compared to cells transfected with scramble control (Figure 5B). Relatively, down-regulation of miR-378 by inhibitors in SW620 cells led to a moderate increase of vimenin protein level (Figure 5B). Meanwhile, apparent alterations of vimentin mRNA expression were also observed by quantitative PCR $(P<0.01$, Figure 5B). It suggested a potential regulation of vimentin by miR-378. Thus, vimentin is likely to be suppressed by miR-378 through translational inhibition and mRNA degradation.

Table 2 Univariate and multivariate analyses of prognostic factors in colorectal cancer

\begin{tabular}{|c|c|c|c|c|c|c|}
\hline \multirow[t]{2}{*}{ Variable } & \multicolumn{3}{|c|}{ Univariate analysis } & \multicolumn{3}{|c|}{ Multivariate analysis } \\
\hline & $\mathrm{HR}$ & $95 \% \mathrm{Cl}$ & $p$-value & $\mathrm{HR}$ & $95 \% \mathrm{Cl}$ & $P$-Value \\
\hline Age (years) & 1.619 & $0.759-3.454$ & 0.213 & & & \\
\hline Gender & 1.121 & $0.521-2.422$ & 0.766 & & & \\
\hline Location & 1.691 & $0.783-3.652$ & 0.181 & & & \\
\hline Histological grading & 1.844 & $0.861-3.949$ & 0.115 & & & \\
\hline Tumor size & 2.414 & $1.123-5.186$ & 0.024 & 2.086 & $0.954-4.563$ & 0.066 \\
\hline Depth of invasion & 2.374 & $1.083-5.202$ & 0.031 & 1.461 & $0.650-3.282$ & 0.358 \\
\hline Lymph node metastasis & 5.286 & $1.996-13.999$ & 0.001 & 5.080 & $1.940-13.554$ & 0.001 \\
\hline Clinicopathological staging & 2.863 & $1.268-6.564$ & 0.013 & & & \\
\hline MiR-378 & 3.165 & $1.381-7.253$ & 0.006 & 2.492 & $1.057-5.876$ & 0.037 \\
\hline
\end{tabular}

HR: hazard ratio, Cl: confidence interval. 


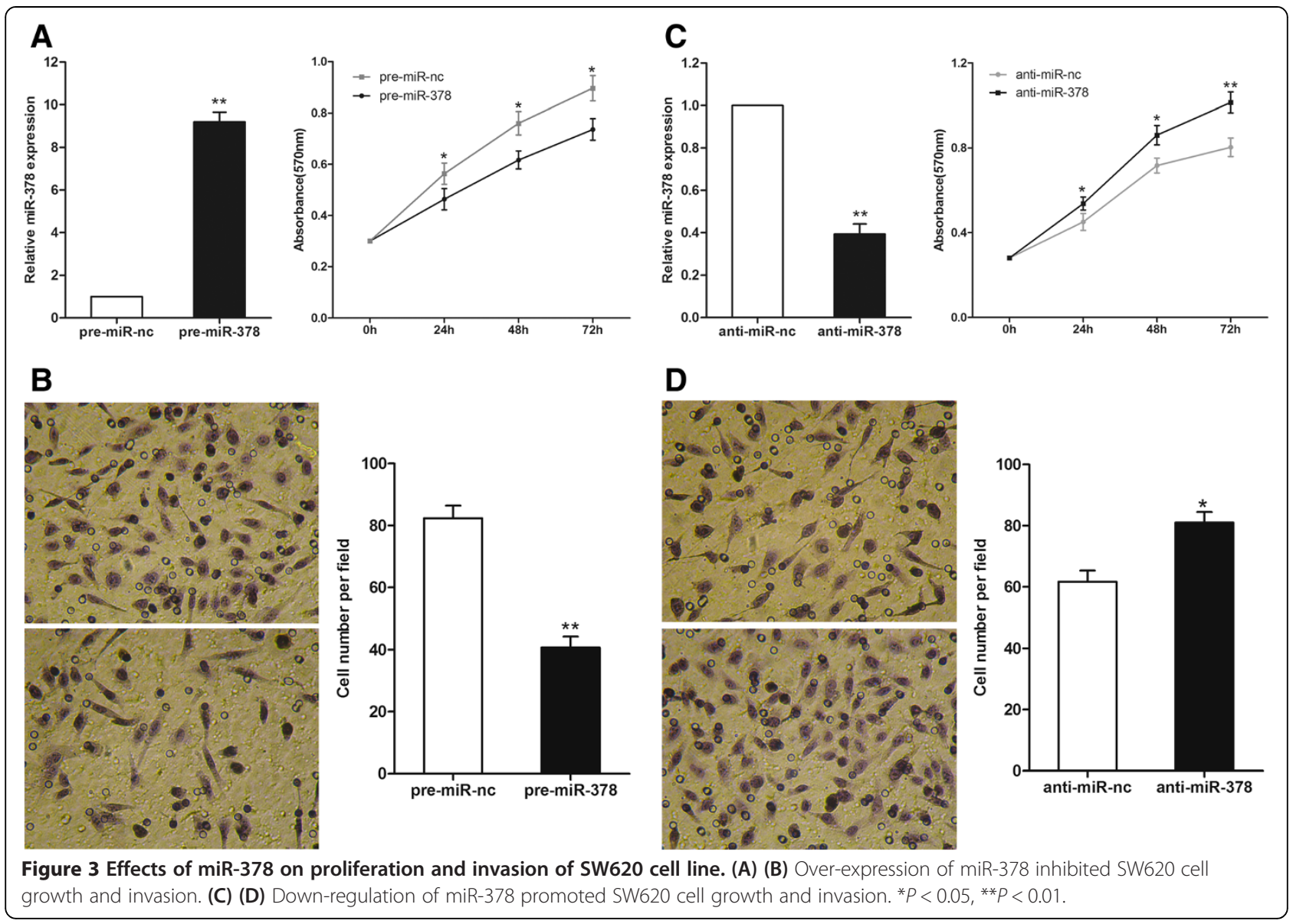

To directly address whether miR-378 binds to the 3 'UTR of target mRNA, we generated a luciferase reporter vector that contain the vimentin 3 '-UTR with the putative miR-378 binding sites. Correspondingly, we also generated a mutant reporter vector which contains the vimentin 3'-UTR with a mutation at the putative miR378 binding site (Figure 5A). As shown in Figure 5C, we observed a marked reduction in luciferase activity in cells transfected with pre-miR-378 compared with premiR-nc transfected cells $(P<0.01)$. In contrast, no change of luciferase was observed in cells transfected with the mutant $3^{\prime}$-UTR constructs. Taken together, these findings indicate that vimentin is a direct, downstream target for miR-378 in SW620 cells.

\section{Discussion}

Several groups have screened for colon cancer-related miRNAs, but limited evidence exists that causally link specific miRNAs to specific functions [21]. Identification of cancer-specific miRNAs and their targets is critical for understanding their roles in tumorigenesis, and may be important for finding out novel prognostic and therapeutic targets.

Accumulating evidence showed that up-regulation of miR-378 was associated with several types of human malignant solid tumors, including those of the glioblastoma, breast cancer and renal cell carcinoma $[12,13,15]$. In these types of cancer, miR-378 seemed to be an oncogene, and enhanced tumor cell survival, promoted tumor growth and metastasis in some tumors via regulation of the target genes $\mathrm{SuFu}$, Fus-1, HMOX1, ESRRG and GABPA [12-15]. However, other studies demonstrated that miR-378 was downregulated in gastric cancer and oral cancer $[11,16]$, and miR-378 may act as tumor suppressors in gastric cancer by negatively regulating the expression of CDK6 and VEGF [16]. Therefore, the function of miR-378 is complicated because it can be oncogenic or a tumor suppressor in different types of cancers. Several studies have been reported that miR-378 was significantly down-regulated in CRC [17-20]. However, the specific mechanism by which the altered expression of miR378 affects tumor development and progression has 


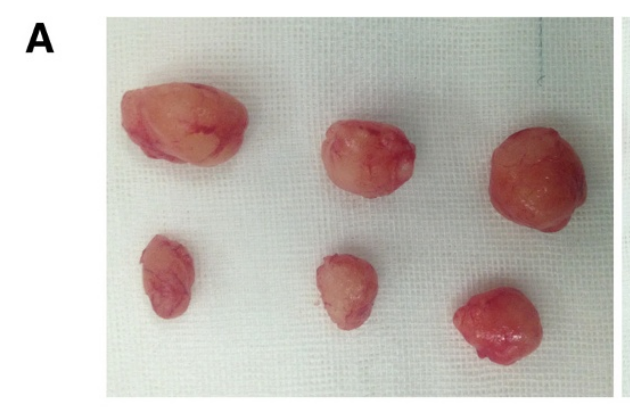

B

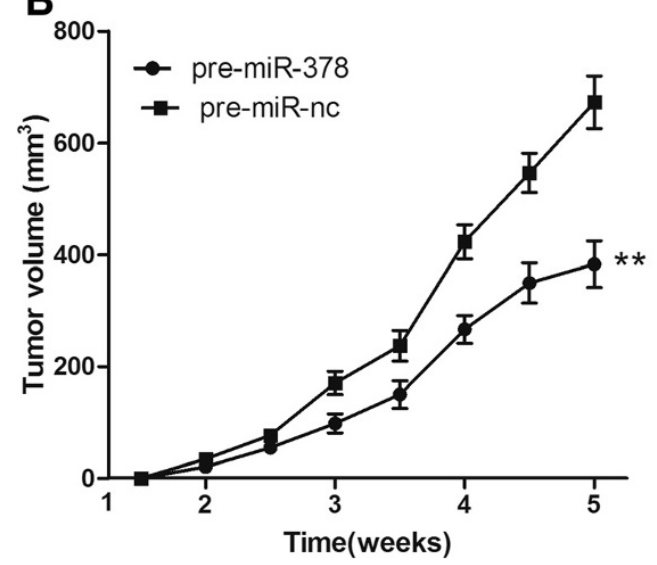

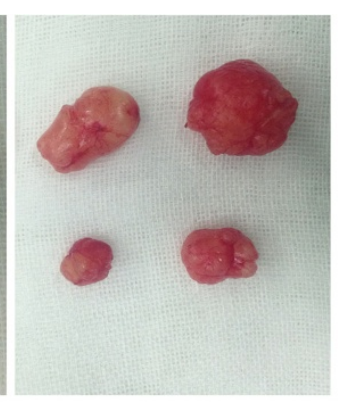

C

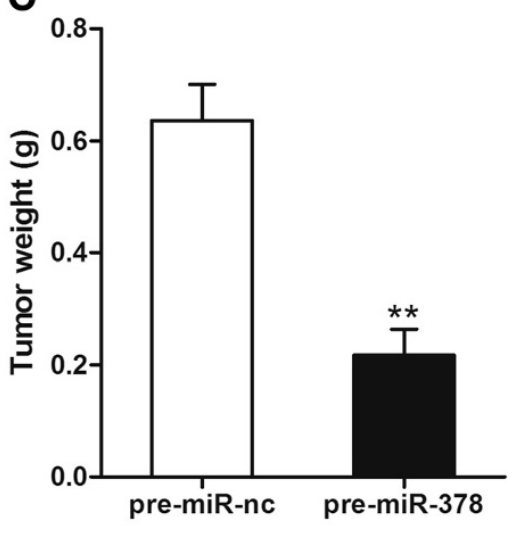

Figure 4 MiR-378 inhibits tumor growth in vivo. (A) Representative image of tumors formed. (B) Growth curve drawn by measuring tumor volumes at the indicated times. (C) Weight of xenograft tumors. ${ }^{*} P<0.01$.

not been elucidated and its involvement in CRC has not been addressed in detail.

In the current study, we further confirmed that miR378 expression was significantly down-regulated in CRC tissue samples and cell lines, and that loss of miR-378 expression was associated with large tumor size, advanced clinical stage, lymph node metastasis and shorter overall survival of the patients with CRC, indicating that miR-378 might be involved in CRC progression and could be used as a potential prognostic biomarker in CRC. Furthermore, over-expression of miR-378 could significantly inhibit cell proliferation and invasion in vitro and tumor growth in vivo. On the contrary, when transfected with miR-378 inhibitors, SW620 cells exhibited stimulated proliferation as well as invasive capabilities. This study first showed that miR-378 may function as a tumor suppressor in CRC.

To explore the mechanisms underlying the inhibition of CRC cell growth and invasion mediated by miR-378, we next set out to identify the potential target genes of miR-378. The bioinformatics analysis indicates that vimentin may be the potential target for miR-378. One of the key molecular steps in the process of distant metastasis includes epithelial-to-mesenchymal transition (EMT) [22], which permits invasion and migration in
CRC [23], and is associated with a poor prognosis in CRC [24]. The intermediate filament protein (IFP) vimentin, expressed in mesenchymal cells, is a wellknown marker for EMT [25]. Vimentin expression and perturbation of E-cadherin-mediated cell adhesion are therefore both regarded as hallmarks of EMTassociated events [26]. A recent report showed that vimentin was one of the predominant overexpressed proteins in the highly metastatic cell line SW620 [27]. Thus, in the present study, SW620 cells were selected as model systems for the study of the molecular events involved in CRC metastasis. A previous study suggested that vimentin methylation was associated with liver metastasis and peritoneal dissemination in colorectal cancer [28]. Vimentin was also reported to be highly expressed in CRC, and high expression of vimentin was found to be associated with lymph node metastasis and disease recurrence in CRC [29,30].

Several pieces of evidence in our study indicate that vimentin is a direct target gene of miR-378 in CRC cancer. Firstly, at both mRNA and protein level, up-regulation of miR-378 expression in SW620 cells effectively suppressed vimentin expression, whereas, downregulation of miR-378 moderately promoted vimentin expression. It suggested a 


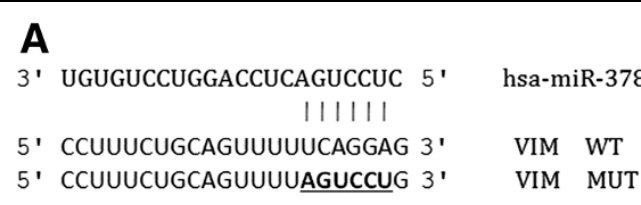

B
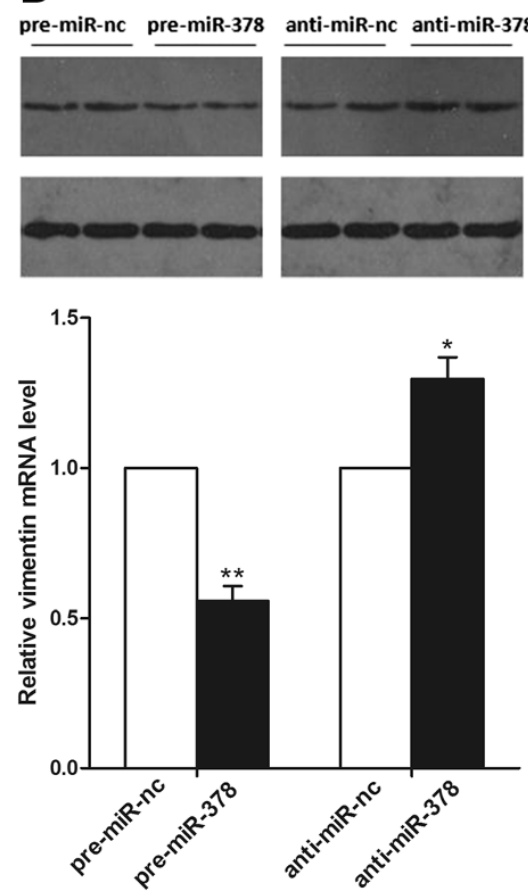

C

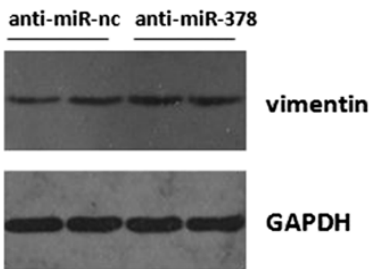

GAPDH

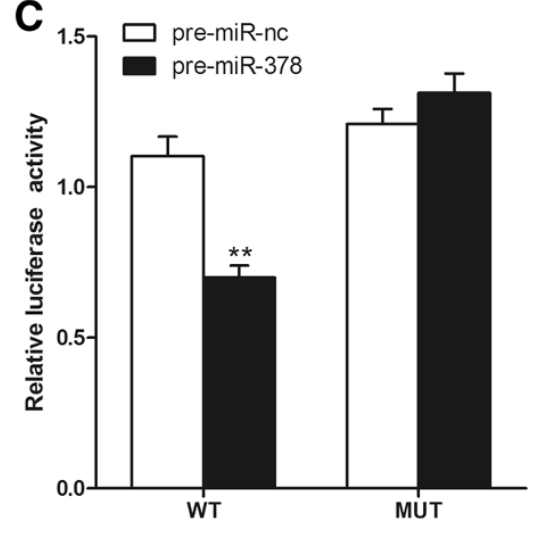

Figure 5 Vimentin is a direct target of miR-378. (A) The wild-type (WT) and mutated (MUT) $3^{\prime} U T R$ of vimentin, with the seed region and base substitutions (bold). (B) The expression levels of vimentin mRNA and protein were detected by qRT-PCR and western blot assays. (C) Ectopic miR-378 expression inhibits wild-type but not mutant vimentin $3^{\prime} U T R$ reporter activity. ${ }^{*} P<0.05$, ${ }^{*} P<0.01$.

potential inverse relevance of miR-378 and vimentin in CRC. Secondly, over-expression of miR-378 significantly reduces the activity of a luciferase reporter containing the 3' UTR sequence of vimentin. In addition, vimentin has been confirmed as a target gene of miR-378 in glioblastoma Cells [30]. When combined with bioinformatic analysis, we concluded vimentin was a target gene of miR-378 in CRC. Taken together, these findings sufficiently consolidated that miR-378 played a suppressive role in cellular proliferation and invasion, at least, in part due to directly inhibiting vimentin expression.

\section{Conclusion}

In summary, our present study showed that miR-378 was down- regulated in CRC tissues and cell lines. And the low expression pattern was observed to be significantly correlated with increased tumor size, advanced clinical stage, lymph node metastasis and worse prognosis. We also found that miR-378 can inhibit tumor growth and invasion partly by targeting vimentin. Our data implicated the potential application of miR-378 as a tumor suppressor in CRC therapy and also as a tumor marker for predicting prognosis.

\section{Competing interests}

The authors declare that they have no competing interests.

\section{Authors' contributions}

$Z G J, X H X$ and LY performed experiments; ZGJ, ZH and ZT designed research and wrote the paper; $Z G J$ and $Z H$ analyzed data. All authors read and approved the final manuscript.

\section{Acknowledgments}

This study was supported by Scientific Research Fund of Sichuan Provincial Education Department of China (CBY12-A-ZD16).

\section{Author details}

'The First Department of General Surgery, The Affiliated Hospital of North Sichuan Medical College, Nanchong, Sichuan, People's Republic of China. ${ }^{2}$ Institute of Hepatobiliary, Pancreatic and Intestinal Disease, North Sichuan Medical College, Nanchong, Sichuan, People's Republic of China. ${ }^{3}$ Department of Pathology, The North Sichuan Medical College, Nanchong, Sichuan, People's Republic of China. ${ }^{4}$ Department of Microbiology and Parasitology, North Sichuan Medical College, Nanchong, Sichuan, People's Republic of China. 
Received: 10 July 2013 Accepted: 12 February 2014

Published: 20 February 2014

\section{References}

1. Center MM, Jemal A, Ward E: International trends in colorectal cancer incidence rates. Cancer Epidemiol Biomarkers Prev 2009, 18(6):1688-1694.

2. Jemal A, Siegel R, Ward E, Murray T, Xu J, Thun MJ: Cancer statistics, 2007. CA Cancer J Clin 2007, 57(1):43-66.

3. Bartel DP: MicroRNAs: genomics, biogenesis, mechanism, and function. Cell 2004, 116(2):281-297.

4. Croce CM, Calin GA: miRNAs, cancer, and stem cell division. Cell 2005, 122(1):6-7.

5. Gregory Rl, Shiekhattar R: MicroRNA biogenesis and cancer. Cancer Res 2005, 65(9):3509-3512.

6. Lu J, Getz G, Miska EA, Alvarez-Saavedra E, Lamb J, Peck D, Sweet-Cordero A, Ebert BL, Mak RH, Ferrando AA, Downing JR, Jacks T, Horvitz HR, Golub TR: MicroRNA expression profiles classify human cancers. Nature 2005, 435(7043):834-838.

7. Volinia S, Calin GA, Liu CG, Ambs S, Cimmino A, Petrocca F, Visone R, lorio M, Roldo C, Ferracin M, Prueitt RL, Yanaihara N, Lanza G, Scarpa A, Vecchione A, Negrini M, Harris CC, Croce CM: A microRNA expression signature of human solid tumors defines cancer gene targets. Proc Natl Acad Sci USA 2006, 103 (7):2257-2261

8. Lujambio A, Calin GA, Villanueva A, Ropero S, Sánchez-Céspedes M, Blanco D, Montuenga LM, Rossi S, Nicoloso MS, Faller WJ, Gallagher WM, Eccles SA, Croce CM, Esteller M: A microRNA DNA methylation signature for human cancer metastasis. Proc Natl Acad Sci U S A 2008, 105(36):13556-13561.

9. Steele CW, Oien KA, McKay CJ, Jamieson NB: Clinical potential of microRNAs in pancreatic ductal adenocarcinoma. Pancreas 2011, 40(8):1165-1171.

10. Wu ZS, Wang CQ, Xiang $R$, Liu X, Ye $S$, Yang XQ, Zhang GH, Xu XC, Zhu T, Wu Q: Loss of miR-133a expression associated with poor survival of breast cancer and restoration of miR-133a expression inhibited breast cancer cell growth and invasion. BMC Cancer 2012, 12:51.

11. Scapoli L, Palmieri A, Lo Muzio L, Pezzetti F, Rubini C, Girardi A, Farinella F, Mazzotta M, Carinci F: MicroRNA expression profiling of oral carcinoma identifies new markers of tumor progression. Int J Immunopathol Pharmacol 2010, 23(4):1229-1234.

12. Redova M, Poprach A, Nekvindova J, lliev R, Radova L, Lakomy R, Svoboda M, Vyzula R, Slaby O: Circulating miR-378 and miR-451 in serum are potential biomarkers for renal cell carcinoma. J Trans/ Med 2012, 10:55.

13. Lee DY, Deng Z, Wang CH, Yang BB: MicroRNA-378 promotes cell survival, tumor growth, and angiogenesis by targeting SuFu and Fus-1 expression. Proc Natl Acad Sci USA 2007, 104(51):20350-20355.

14. Chen LT, Xu SD, Xu H, Zhang JF, Ning JF, Wang SF: MicroRNA-378 is associated with non-small cell lung cancer brain metastasis by promoting cell migration, invasion and tumor angiogenesis. Med Oncol 2012, 29(3):1673-1680.

15. Eichner LJ, Perry MC, Dufour CR, Bertos N, Park M, St-Pierre J, Giguere V: miR-378(*) mediates metabolic shift in breast cancer cells via the PGC-1beta/ ERRgamma transcriptional pathway. Cell Metab 2010, 12(4):352-361.

16. Deng H, Guo Y, Song H, Xiao B, Sun W, Liu Z, Yu X, Xia T, Cui L, Guo J: MicroRNA-195 and microRNA-378 mediate tumor growth suppression by epigenetical regulation in gastric cancer. Gene 2013, 518(2):351-359.

17. Callari M, Dugo M, Musella V, Marchesi E, Chiorino G, Grand MM, Pierotti MA, Daidone MG, Canevari S, De Cecco L: Comparison of microarray platforms for measuring differential microRNA expression in paired normal/cancer colon tissues. PLoS One 2012, 7(9):e45105.

18. Faltejskova P, Svoboda M, Srutova K, Mlcochova J, Besse A, Nekvindova J, Radova L, Fabian P, Slaba K, Kiss I, Vyzula R, Slaby O: Identification and functional screening of microRNAs highly deregulated in colorectal cancer. J Cell Mol Med 2012, 16(11):2655-2666.

19. Mosakhani N, Sarhadi VK, Borze I, Karjalainen-Lindsberg ML, Sundström J, Ristamäki R, Osterlund P, Knuutila S: MicroRNA profiling differentiates colorectal cancer according to KRAS status. Genes Chromosomes Cancer 2012, 51(1):1-9.

20. Wang YX, Zhang XY, Zhang BF, Yang CQ, Chen XM, Gao HJ: Initial study of microRNA expression profiles of colonic cancer without lymph node metastasis. J Dig Dis 2010, 11(1):50-54.

21. Garofalo M, Croce CM: microRNAs: Master regulators as potential therapeutics in cancer. Annu Rev Pharmacol Toxicol 2011, 51:25-43.

22. Kalluri R, Weinberg RA: The basics of epithelial-mesenchymal transition. J Clin Invest 2009, 119(6):1420-1428
23. Brabletz T, Hlubek F, Spaderna S, Schmalhofer O, Hiendlmeyer E, Jung A, Kirchner T: Invasion and metastasis in colorectal cancer: epithelialmesenchymal transition, mesenchymal-epithelial transition, stem cells and beta-catenin. Cells Tissues Organs 2005, 179(1-2):56-65.

24. Spaderna S, Schmalhofer O, Hlubek F, Berx G, Eger A, Merkel S, Jung A, Kirchner T, Brabletz T: A transient, EMT-linked loss of basement membranes indicates metastasis and poor survival in colorectal cancer. Gastroenterology 2006, 131(3):830-840.

25. Ivaska J, Pallari HM, Nevo J, Eriksson JE: Novel functions of vimentin in cell adhesion, migration, and signaling. Exp Cell Res 2007, 313(10):2050-2062.

26. Onder TT, Gupta PB, Mani SA, Yang J, Lander ES, Weinberg RA: Loss of E-cadherin promotes metastasis via multiple downstream transcriptional pathways. Cancer Res 2008, 68(10):3645-3654

27. Hur K, Toiyama Y, Takahashi M, Balaguer F, Nagasaka T, Koike J, Hemmi H, Koi M, Boland CR, Goel A: MicroRNA-200c modulates epithelial-tomesenchymal transition (EMT) in human colorectal cancer metastasis. Gut 2012, 62(9):1315-1326.

28. Shirahata A, Sakata M, Sakuraba K, Goto T, Mizukami H, Saito M, Ishibashi K, Kigawa G, Nemoto H, Sanada Y, Hibi K: Vimentin methylation as a marker for advanced colorectal carcinoma. Anticancer Res 2009, 29(1):279-281.

29. Mclnroy L, Määttä A: Down-regulation of vimentin expression inhibits carcinoma cell migration and adhesion. Biochem Biophys Res Commun 2007, 360(1):109-114.

30. Ngan CY, Yamamoto H, Seshimo I, Tsujino T, Man-i M, Ikeda Jl, Konishi K, Takemasa I, Ikeda M, Sekimoto M, Matsuura N, Monden M: Quantitative evaluation of vimentin expression in tumour stroma of colorectal cancer. Br J Cancer 2007, 96(6):986-992.

doi:10.1186/1471-2407-14-109

Cite this article as: Zhang et al:: MiR-378 is an independent prognostic factor and inhibits cell growth and invasion in colorectal cancer. BMC Cancer 2014 14:109.

\section{Submit your next manuscript to BioMed Central and take full advantage of:}

- Convenient online submission

- Thorough peer review

- No space constraints or color figure charges

- Immediate publication on acceptance

- Inclusion in PubMed, CAS, Scopus and Google Scholar

- Research which is freely available for redistribution

Submit your manuscript at www.biomedcentral.com/submit
C) Biomed Central 